\title{
Using a slit lamp-mounted digital high-speed camera for dynamic observation of phakic lenses during eye movements: a pilot study
}

This article was published in the following Dove Press journal:

Clinical Ophthalmology

18 July 2014

Number of times this article has been viewed

\section{Martin Alexander Leitritz \\ Focke Ziemssen \\ Karl Ulrich Bartz-Schmidt Bogomil Voykov}

Centre for Ophthalmology, University Eye Hospital, Eberhard Karls University of Tübingen, Tübingen, Germany
Correspondence: Martin Alexander Leitritz Centre for Ophthalmology, University Eye Hospital, Eberhard Karls University of Tübingen, Schleichstrasse 12, 72076 Tübingen, Baden-Württemberg, Germany

Tel +49 707| 298476

Fax +49 707I 294676

Email martin.leitritz@med.uni-tuebingen.de
Purpose: To evaluate a digital high-speed camera combined with digital morphometry software for dynamic measurements of phakic intraocular lens movements to observe kinetic influences, particularly in fast direction changes and at lateral end points.

Materials and methods: A high-speed camera taking 300 frames per second observed movements of eight iris-claw intraocular lenses and two angle-supported intraocular lenses. Standardized saccades were performed by the patients to trigger mass inertia with lens position changes. Freeze images with maximum deviation were used for digital software-based morphometry analysis with ImageJ.

Results: Two eyes from each of five patients (median age 32 years, range $28-45$ years) without findings other than refractive errors were included. The high-speed images showed sufficient usability for further morphometric processing. In the primary eye position, the median decentrations downward and in a lateral direction were $-0.32 \mathrm{~mm}$ (range -0.69 to 0.024 ) and $0.175 \mathrm{~mm}$ (range -0.37 to 0.45 ), respectively. Despite the small sample size of asymptomatic patients, we found a considerable amount of lens dislocation. The median distance amplitude during eye movements was $0.158 \mathrm{~mm}$ (range $0.02-0.84$ ). There was a slight positive correlation $(r=0.39$, $P<0.001)$ between the grade of deviation in the primary position and the distance increase triggered by movements.

Conclusion: With the use of a slit lamp-mounted high-speed camera system and morphometry software, observation and objective measurements of iris-claw intraocular lenses and anglesupported intraocular lenses movements seem to be possible. Slight decentration in the primary position might be an indicator of increased lens mobility during kinetic stress during eye movements. Long-term assessment by high-speed analysis with higher case numbers has to clarify the relationship between progressing motility and endothelial cell damage.

Keywords: intraocular lens, high-speed camera, phakic lens

\section{Introduction}

Besides angle-supported intraocular lenses (ASIOLs), iris-claw intraocular lenses (ICIOLs) are also designed as anterior chamber lenses. First-generation iris-claw models were launched in 1953, and optimized designs of these are now used not only in cases of aphakia (eg, traumatic) or after intracapsular cataract extraction ${ }^{1,2}$ but since 1986 they have also been used in phakic eyes (phakic intraocular lenses [PIOLs]) to correct refractive errors. ${ }^{3}$ Nowadays, Artisan ${ }^{\circledR} /$ Artiflex $^{\circledR}$ ICIOLs (Ophthec, Groningen, the Netherlands)/Verisyse ${ }^{\circledR}$ (Abbott Medical Optics, Santa Ana, CA, USA) and Cachet ${ }^{\circledR}$ (Novartis International AG, Basel, Switzerland) ASIOLs are available in different versions depending on optic power and the need for correction of astigmatism.

Several clinical trials with variable results partially reported that the position of ICIOLs and the morphometry of the anterior chamber (eg, deep or shallow anterior 
chambers, ${ }^{4}$ white-to-white distance, or sulcus diameter) may have consequences, eg, endothelial cell $\operatorname{loss}^{4,5}$ or chronic inflammations of the iris. ${ }^{6,7}$ To measure in more realistic conditions, investigations using Scheimpflug photography or ultrasound biomicroscopy have also been performed. ${ }^{8,9}$ In 1984, Miller and Doane used analog high-speed imaging to investigate movements of ASIOLs and ICIOLs (mainly Binkhorst type).${ }^{10}$ Due to technical limitations, only moderate changes of the gaze position were investigated in patients after intracapsular cataract extraction. ${ }^{10}$

The aim of our pilot study was to evaluate a digital highspeed camera setting (mounted on a slit lamp) to measure the movements of PIOLs not only at a standstill or within small globe movements but also in fast direction changes in the primary position and at lateral end points.

\section{Materials and methods}

For capturing lens positions during eye movements, a high-speed charge-coupled device camera (Genie HM640; Teledyne Dalsa, Waterloo, ON, Canada) with a resolution of $640 \times 480$ pixels and speed of 300 frames per second ( 8 bit) was mounted ( $\mathrm{C}$ mount) on the video adapter ( $\mathrm{f} 75$; Haag-Streit, Köniz, Switzerland) of a conventional slit lamp (BQ900; Haag-Streit). For capturing high-speed videos, optimized software (Motion Traveller version 2.28.0.5173; Imaging Solutions, Eningen, Germany) was used. Illumination was achieved by using the total slit $(8 \times 8 \mathrm{~mm})$ with the brightest illumination settings. Furthermore, a cold-light source (FlexiLux 3000; Schölly Fiberoptic, Denzlingen, Germany) was used for a more homogeneous illumination. The technical harmlessness of the setting was approved by the in-house technical assistance.

Before the high-speed video session, a standard slitlamp examination was performed by an experienced ophthalmologist to survey for loose fixations, decentrations, and detectable abnormalities of the lens. Lentodonesis of the artificial lens was defined as 0 if absent, 1 if only slightly visible, or 2 in cases with obvious lens movements. Patients were asked whether they noticed any kind of shaking images.

Each eye of a patient was filmed separately. Sequential capturing positions were frontal without globe movement and both lateral end points of globe movements. Therefore, the slit lamp was adjusted in a parallel perspective (Figure 1). Thereafter, the patients were told to move their eyes reiteratively from one end position to the other (ie, from up to down or left to right; Figure 2, Table 1). To trigger the kinetic effects of artificial lenses, horizontal and vertical eye movements were performed with and without short stops in the primary position.

Video sequences were exported as uncompressed audiovideo interleaved (AVI) files (30 frames per second). Images were exported out of the created AVI files and saved in tagged image file (TIF; resolution $640 \times 480$ ) format. Position measurements were performed using ImageJ (http://imagej.nih. gov/ii). ${ }^{11}$ Only images with clearly delimited pupil and lens margins were included. For measurements of maximal lens deviations only video-frames with the peak of movements (backshoots and overshoots) ${ }^{12}$ were used. The center of the pupil was estimated by adapting a circle within the pupil and defining its centroid. With the same method, the centroid of the lens optic was measured. Afterward, the distance and angle between the center of the lens and the center of the pupil were measured for all positions for frontal and endpoint positions (Figure 3 ).

The collected data were descriptively analyzed using a statistical program (JMP 10.0; SAS Institute Inc., Cary, NC, USA). All data were anonymously analyzed in accordance with the strict German directives on information security and
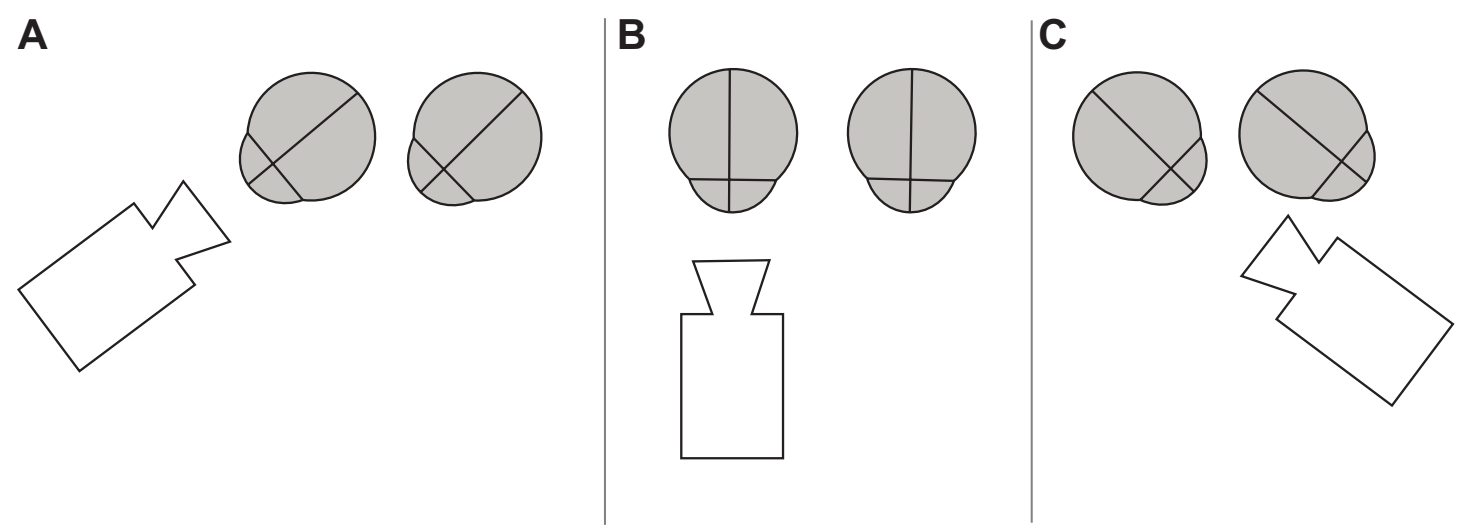

Figure I Schematic drawing of camera positions while video capturing side glance to the right (A), primary position (B), and side glance to the left (C) for analysis of the right eye. 

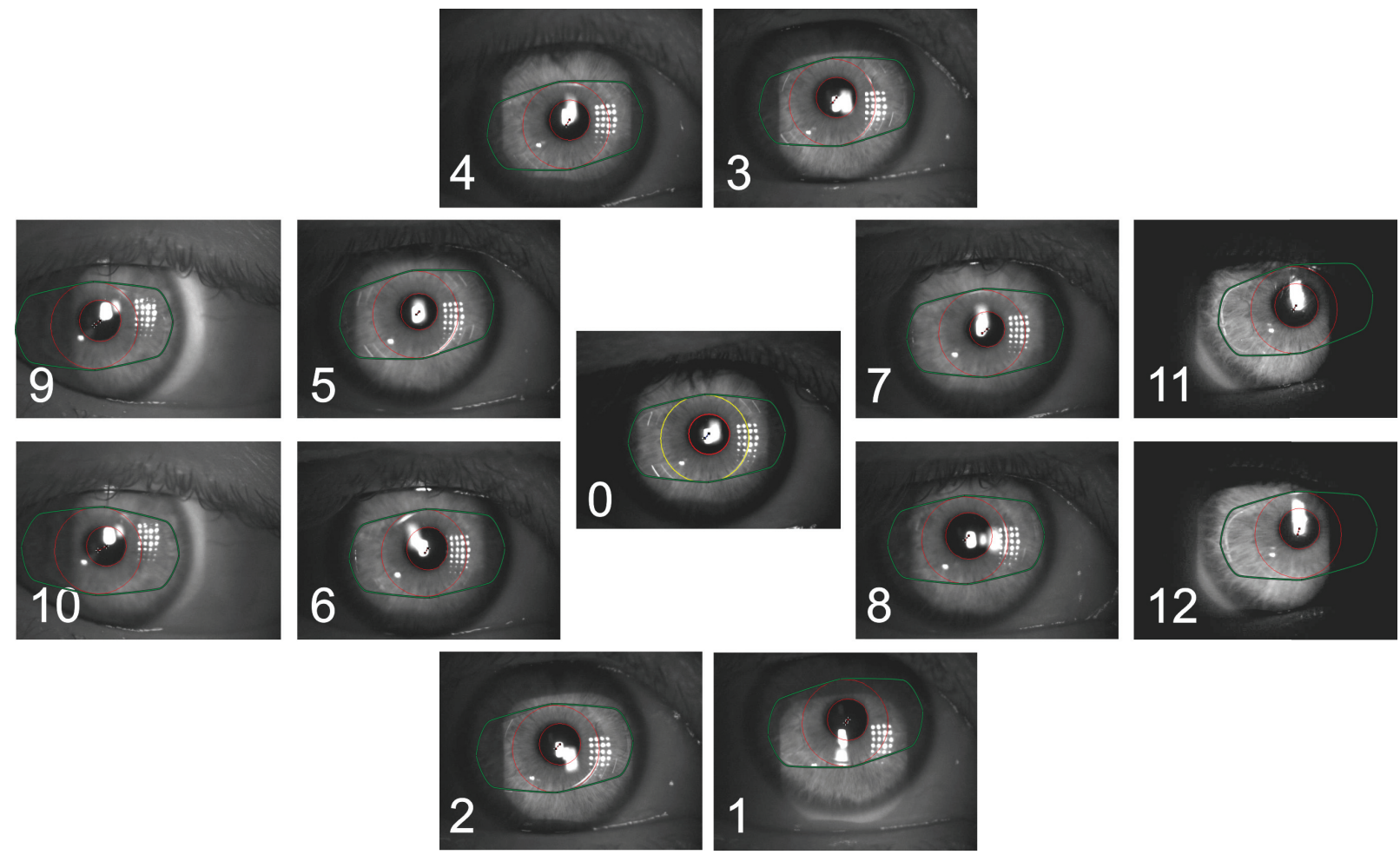

Figure 2 Images of different positions with overlays of the pupil shape and lens positions.

Notes: The numbers on the pictures denote the position and the colored markings on the overlays signify as follows: green, lens borders; big red circle, lens optic; small red circle, pupil margin; yellow circle, lens optic in primary position; cross-hairs, mark the deviation between centroid of pupil and lens optic.

data protection. Written informed consent was obtained from all patients before the examination. The investigation followed the tenets of the Declaration of Helsinki. Approval of the local ethics committee (Tübingen) was obtained in advance.

\section{Results}

In this pilot study, two eyes from each of five patients (median age 32 years, range $28-45$ years) were included. For further patient characteristics, see Table 2. All patients had undergone refractive surgery because of myopia or astigmatism.

Table I Measurement positions and their defined coding

\begin{tabular}{cl}
\hline Code & Position \\
\hline 0 & Primary position \\
1 & Motion from the primary position to the bottom \\
2 & Motion from the bottom to the primary position \\
3 & Motion from the primary position to the top \\
4 & Motion from the top to the primary position \\
5 & Motion from the primary position to the right \\
6 & Motion from the right to the primary position \\
7 & Motion from the primary position to the left \\
8 & Motion from the left to the primary position \\
9 & Motion to the right end position \\
10 & Motion outgoing from the right end position \\
11 & Motion to the left end position \\
12 & Motion outgoing from the left end position \\
\hline
\end{tabular}

No other abnormalities (eg, glaucoma, lens pseudoexfoliation) existed at the time of surgery or study examination. No patients reported shaking images. The high-speed camera showed good functionality. In all cases, high-speed imaging was possible, and there were no resulting problems due to reflections or blurry images. In two patients, positions 3 and 4 were not sufficiently observable due to a small palpebral fissure.

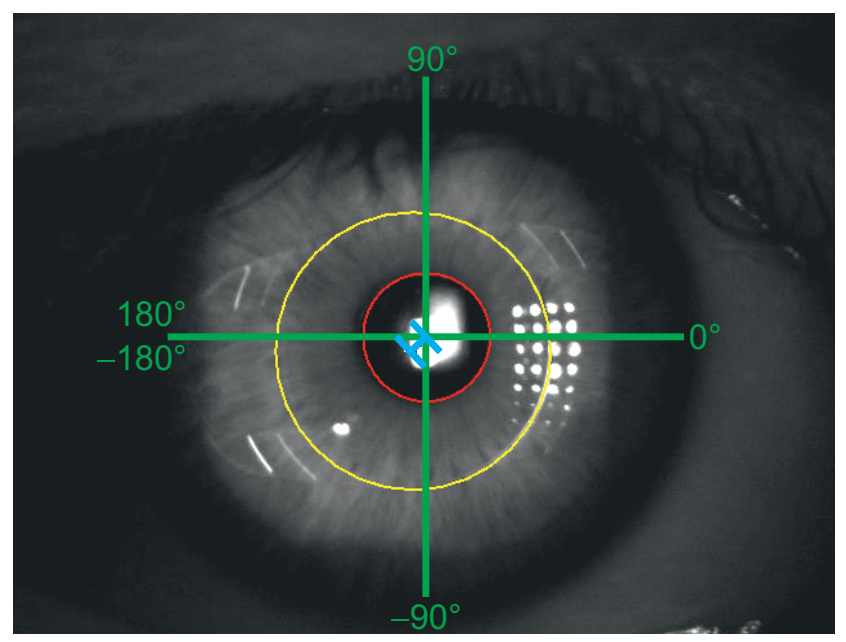

Figure 3 Scheme of measurement conventions.

Notes: Measurements of the deviation direction followed the green sketched graduation. The red and yellow circles mark the borders of the pupil and of the lens optic. The blue line marks the distance between the centers of the pupil and lens optic. 
Table 2 Patient characteristics

\begin{tabular}{lllllll}
\hline ID & Sex & Age (years) & Years since surgery & Lens model & Optic diameter (mm) & Lentodonesis* \\
\hline I & F & 43 & 6 & Artisan $^{\circledR}$ toric & 5 & I \\
2 & M & 32 & 4 & Artisan $^{\circledast}$ & 6 & 0 \\
3 & M & 28 & 6 & Artiflex $^{\circledast}$ & 6 & 1 \\
4 & M & 32 & 6 & Artisan $^{\circledast}$ toric & 5 & 0 \\
5 & F & 45 & 3 & Cachet $^{\circledR}$ & 6 & 0 \\
\hline
\end{tabular}

Notes: ${ }^{*}$, none; I, slight; 2, obvious. Artisan ${ }^{\circledR}$ (Ophthec, Groningen, the Netherlands); Cachet ${ }^{\circledR}$ (Novartis International AG, Basel, Switzerland); Artiflex ${ }^{\circledR}$, (Ophthec, Groningen, the Netherlands).

Abbreviations: $F$, female; $M$, male.

In the primary eye position, except in one eye (ASIOL), all lenses were positioned lower (negative $y$-values) in relation to the center of the pupils, with a median of $-0.32 \mathrm{~mm}$ (range -0.69 to 0.024 ) (Figure 4). Subanalysis of different lens models showed a median distance downward of $-0.51 \mathrm{~mm}$ (range -0.69 to -0.33 ) for the Artifle ${ }^{\circledR},-0.34 \mathrm{~mm}$ (range -0.47 to -0.12 ) for the $\operatorname{Artisan}^{\circledR}$, and $-0.18 \mathrm{~mm}$ for one of two Cachet $^{\circledR}$ (second one $0.024 \mathrm{~mm}$ upward). The median deviation in the lateral direction was $0.175 \mathrm{~mm}$ (range -0.37 to 0.45 ). The median absolute distance and angle between the center points were $0.373 \mathrm{~mm}$ (range $0.221-0.742$ ) and $-76.143^{\circ}$ (range $-149^{\circ}$ to $5.711^{\circ}$ ), respectively.

The median distance amplitude of movements that were measured in positions $1-12$ was $0.158 \mathrm{~mm}$ (range $0.02-0.84 \mathrm{~mm}$ ) (Figure 5). Subanalysis of different lens models showed a median distance amplitude of $0.183 \mathrm{~mm}$ (range $0.04-0.84 \mathrm{~mm}$ ) for the Artiflex ${ }^{\circledR}, 0.15 \mathrm{~mm}$ (range $0.02-0.47 \mathrm{~mm}$ ) for the Artisan ${ }^{\circledR}$, and $0.16 \mathrm{~mm}$ (range $0.03-0.44 \mathrm{~mm}$ ) for the Cachet $^{\circledR}$. There was a positive correlation $(r=0.39, P<0.001)$

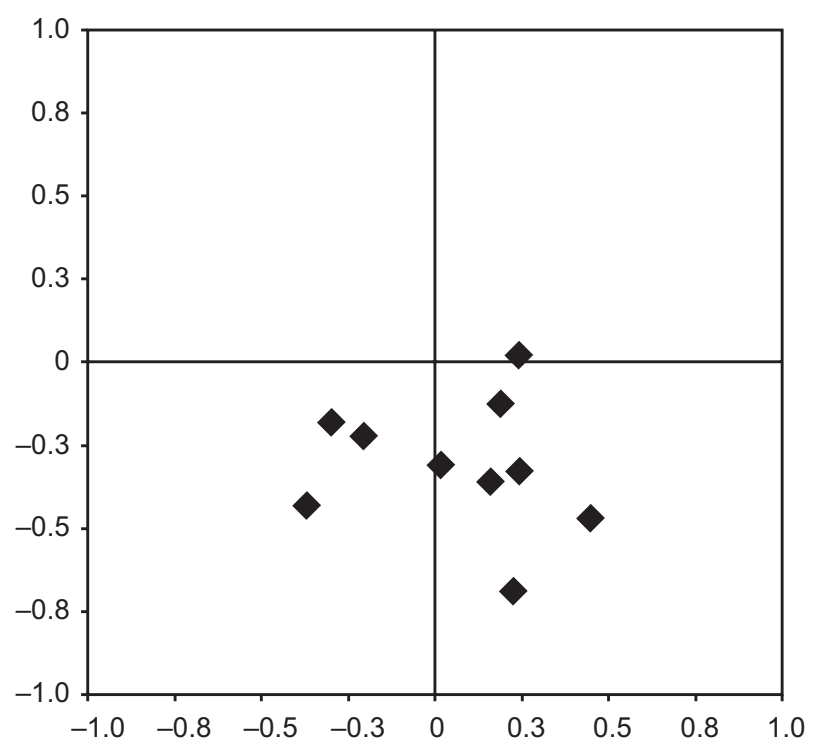

Figure 4 Positions of the lens center in relation to the pupil center.

Notes: The $x$-axis shows the distance in the horizontal direction $(\mathrm{mm})$, the $y$-axis shows the distance in the vertical direction $(\mathrm{mm})$. between the distance of the optic center from the pupil center in the primary position and the grade of the distance increase triggered by movements.

Simplifying the different positions only to middle positions (codes 1-8) and end positions (codes 9-12) for all lens types resulted in a median distance amplitude of movements of $0.14 \mathrm{~mm}$ (range $0.02-0.70 \mathrm{~mm}$ ) and $0.18 \mathrm{~mm}$ (range $0.03-0.84 \mathrm{~mm}$ ), respectively (Figure 6). The median change of the angles was $3.96^{\circ}$ (range $-105.72^{\circ}$ to $69.75^{\circ}$ ), which showed a negative correlation $(-0.3)$ with median distance amplitude over all lens types.

\section{Discussion}

In this pilot study, we were able to discover the function of a slit lamp-mounted high-speed camera system and a subsequent morphometry of images to record kinetic influences on the position of ICIOLs and ASIOLs in phakic eyes. Measurement of varying ICIOL and ASIOL positions was feasible in fast direction changes and at lateral end points.

PIOLs are reversible, ${ }^{13}$ maintain accommodation,,${ }^{14}$ and are used in patients with high refractive errors or in cases with contraindications for corneal refractive procedures (eg, thinned cornea, scotopic pupil size). ${ }^{1,15}$ There are several known possible complications with PIOLs (eg, corneal endothelial cell loss, elevation of intraocular pressure $)^{16,17}$ that can be related to their position within the eye segments. ${ }^{18}$ Based on these complications, many investigations measured the location of ICIOLs $^{5,9,15}$ and ASIOLs ${ }^{4,19}$ and their physiological effects. Examination techniques like optical coherence tomography, biometry, or Scheimpflug imaging do not allow the recording of short-term position changes that can appear based on kinetic effects during fast eye movements. Cheng et al, ${ }^{20} \mathrm{Jacobs}$ et al, ${ }^{21}$ and Miller and Doane ${ }^{10}$ demonstrated the movements of IOLs using high-speed-imaging, but not in phakic individuals and only after short-distance eye movements. As far as the authors know, position-determining investigations of PIOLs have been performed in various positions ${ }^{9}$ or during accommodation, ${ }^{14,19,22}$ but not during fast eye movements. 


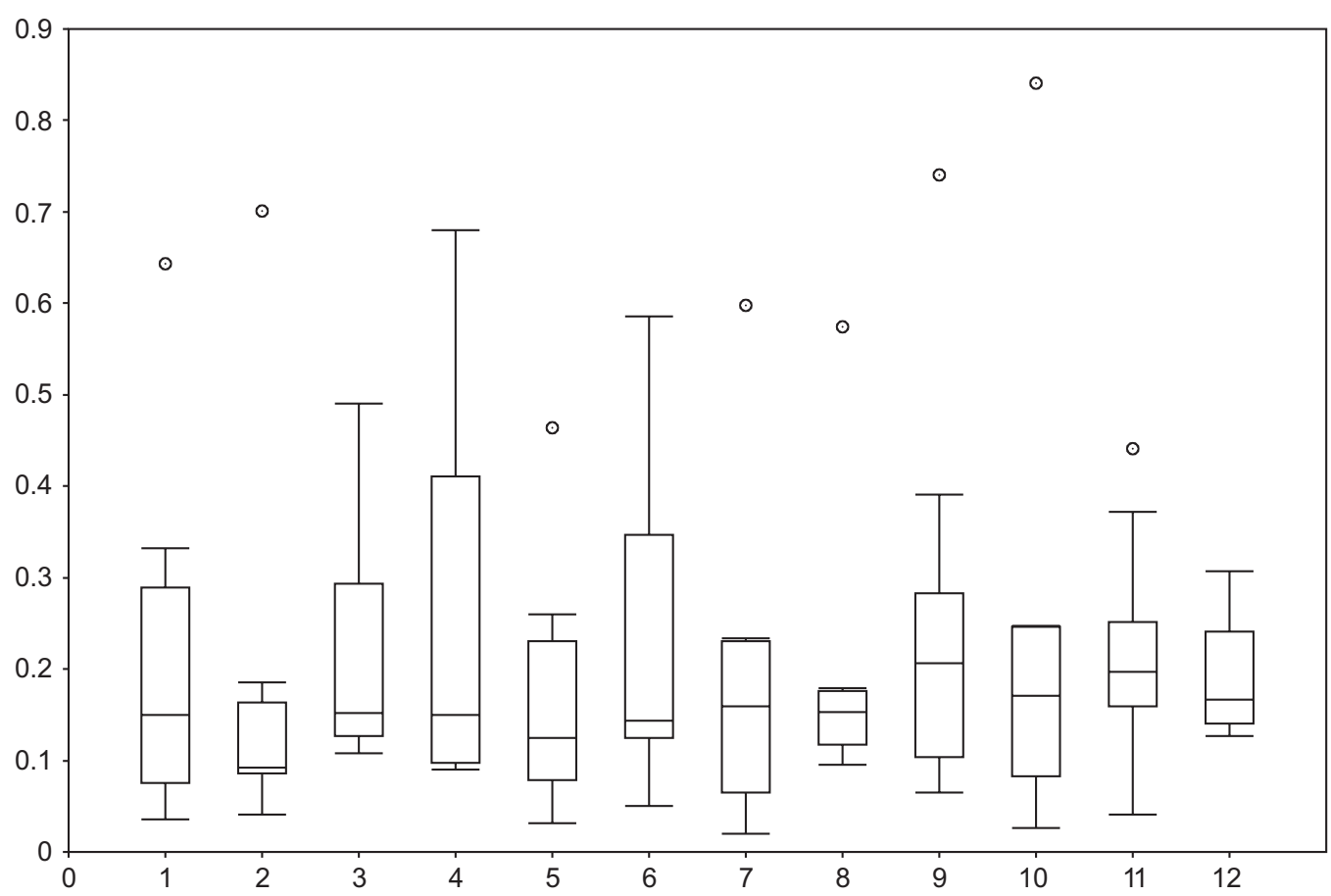

Figure 5 Median distance amplitudes in millimeters ( $y$-axis) of the lenses in different positions (x-axis) in relation to the primary position. Notes: Box-and-whisker plots show $5 \%$ and $95 \%$ quartiles (whiskers), $25 \%$ and $75 \%$ quartiles (box), and the median (marked by a line).

Despite the small case series, we tried not to lump all lens types together, and tried a careful analysis of subgroups. The subsequent analysis of the selected "peak lens deviation" freeze images within our small series to evaluate technical feasibility showed a low-lying lens position relative to the pupil center in nine of ten eyes. Possible causes for these observations are implantation position, looseness of the iris or fixation points, shifting haptic phenomenon, ${ }^{23}$ and gravity

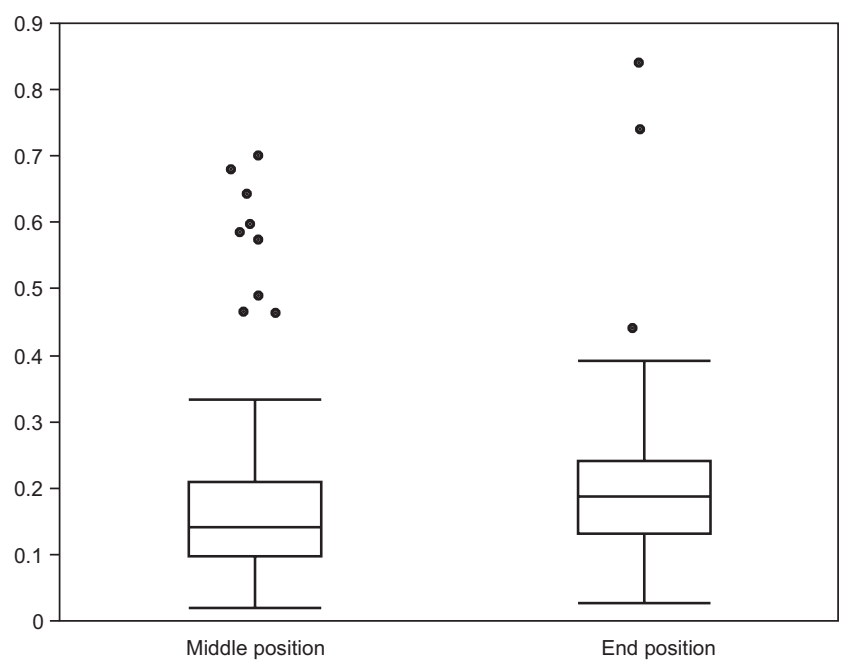

Figure 6 Median distance amplitudes in millimeters (y-axis) of the lenses in middle positions (codes I-8) and end positions (codes 9-12) (x-axis).

Notes: Box-and-whisker plots show 5\% and $95 \%$ quartiles (whiskers), $25 \%$ and $75 \%$ quartiles (box), and the median (marked by a line). forces "pulling" the lenses to negative vertical values. Also, other investigations described decentrations of ICIOL models. Menezo et $\mathrm{al}^{24}$ reported decentrations of up to $1 \mathrm{~mm}$, while Pérez-Santonja et $\mathrm{al}^{25}$ described a decentration greater than $0.5 \mathrm{~mm}$ in $14(43 \%)$ of 32 eyes for Worst-Fechner ICIOLs.

Although the median amplitude over all measured lenses was low, our investigation showed explicit differences for single lenses. Moreover, we could see that higher movement amplitudes could be expected the higher the distance between the lens center and the pupil center at the primary position. But facing the small case numbers, we have to be careful in drawing conclusions. Causes for higher amplitudes in end positions could be loose fixations or increasing kinetic effects in cases of forceful accelerations or decelerations. Furthermore, motions of the pupil, as reported by Nyström et $\mathrm{al}^{26}$ could have influenced our observations. An alternative method to define reference coordinates for deviation measurements could be seen in using Purkinje images. With this method also, movements of the natural lens in normal subjects could be observed. ${ }^{27}$

We demonstrated the feasibility of our video-capturing setting using a slit lamp-mounted high-speed camera for dynamic observations of short-term lens movements in all investigated patients and in various positions of the eyes. Following our first analysis with a reduced number of 
patients, further measurements with our high-speed system seem to be reasonable to detect lens positions and movements in more cases and with a prolonged follow-up time, and to test parameters like interobserver agreement or correlations of lens movements and anterior chamber morphology. Hereafter, the system could be used, eg, to do further investigations of lens stability in patients with unexplained endothelial cell loss.

\section{Limitations}

The number of patients in our feasibility investigations does not allow any further statistical calculations or conclusions for diverse lens designs. Also, although the nonstandardized pupil had a limiting effect, we opted not to influence pupil movements (eg, with atropine, pilocarpine) to avoid effects on the mounting of the lens haptics of ICIOLs. Furthermore, motions of the pupils and their center could have interfered with our measurements, and with higher case numbers differences between horizontal, vertical, or oblique saccades should be evaluated.

\section{Conclusion}

With the use of a simple slit lamp-mounted high-speed camera system, the dynamic observation of movements of ICIOLs and ASIOLs is possible. The images allow detailed measurements of lens movements in various positions. Slight decentration in the primary position might be an indicator of increased lens mobility during kinetic stress during eye movements. With the small case numbers, further investigations within a bigger population are planned. Long-term assessment by high-speed analysis has to clarify the relationship between progressing motility and endothelial cell damage.

\section{Acknowledgments}

Many thanks to Dieter Schwenkel and his team from Imaging Solutions (Eningen, Germany) for the great technical assistance. We acknowledge support by Deutsche Forschungsgemeinschaft and the Open Access Publishing Fund of Tübingen University.

\section{Disclosure}

The authors report no conflicts of interest in this work.

\section{References}

1. Guell JL, Morral M, Kook D, Kohnen T. Phakic intraocular lenses part 1: Historical overview, current models, selection criteria, and surgical techniques. J Cataract Refract Surg. 2010;36(11):1976-1993.

2. Worst JG, van der Veen G, Los LI. Refractive surgery for high myopia. The Worst-Fechner biconcave iris claw lens. Doc Ophthalmol. 1990; 75(3-4):335-341.
3. Fechner PU, van der Heijde GL, Worst JG. [Intraocular lens for the correction of myopia of the phakic eye]. Klin Monbl Augenheilkd. 1988;193(1):29-34. German.

4. Saxena R, Boekhoorn SS, Mulder PG, Noordzij B, van Rij G, Luyten GP. Long-term follow-up of endothelial cell change after Artisan phakic intraocular lens implantation. Ophthalmology. 2008;115(4): 608-613.e1

5. Doors M, Cals DW, Berendschot TT, et al. Influence of anterior chamber morphometrics on endothelial cell changes after phakic intraocular lens implantation. J Cataract Refract Surg. 2008;34(12):2110-2118.

6. Pérez-Santonja JJ, Iradier MT, Benítez del Castillo JM, Serrano JM, Zato MA. Chronic subclinical inflammation in phakic eyes with intraocular lenses to correct myopia. J Cataract Refract Surg. 1996;22(2): 183-187.

7. Senthil S, Reddy KP. A retrospective analysis of the first Indian experience on Artisan phakic intraocular lens. Indian J Ophthalmol. 2006;54(4):251-255.

8. Yu AY, Lin ZD, Chen XQ, Cai XY, Liu YZ, Luo SK. Position of myopic iris-claw phakic intraocular lens by Scheimpflug photography and ultrasound biomicroscopy. Eye (Lond). 2008;22(2):233-239.

9. Schöpfer K, Berger A, Korb C, Stoffelns BM, Pfeiffer N, Sekundo W. Position-dependent accommodative shift of retropupillary fixated iris-claw lenses. Graefes Arch Clin Exp Ophthalmol. 2012;250(12): $1827-1834$

10. Miller D, Doane MG. High-speed photographic evaluation of intraocular lens movements. Am J Ophthalmol. 1984;97(6):752-759.

11. Rasband WS. ImageJ. Bethesda (MD): US National Institutes of Health; 1997.

12. Deubel H, Bridgeman B. Fourth Purkinje image signals reveal eye-lens deviations and retinal image distortions during saccades. Vision Res. 1995;35(4):529-538.

13. Güell JL, Morral M, Gris O, Gaytan J, Sisquella M, Manero F. Fiveyear follow-up of 399 phakic Artisan-Verisyse implantation for myopia, hyperopia, and/or astigmatism. Ophthalmology. 2008;115(6): 1002-1012.

14. Güell JL, Morral M, Gris O, Gaytan J, Sisquella M, Manero F. Evaluation of Verisyse and Artiflex phakic intraocular lenses during accommodation using Visante optical coherence tomography. J Cataract Refract Surg. 2007;33(8):1398-1404.

15. Kohnen T, Cichocki M, Koss MJ. Position of rigid and foldable irisfixated myopic phakic intraocular lenses evaluated by Scheimpflug photography. J Cataract Refract Surg. 2008;34(1):114-120.

16. Kohnen T, Kook D, Morral M, Güell JL. Phakic intraocular lenses: part 2: results and complications. J Cataract Refract Surg. 2010;36(12): 2168-2194.

17. Lovisolo CF, Reinstein DZ. Phakic intraocular lenses. Surv Ophthalmol. 2005;50(6):549-587.

18. Taneri S, Oehler S, Koch JM, Heiligenhaus A. Hypermotility of an irisfixated anterior chamber phakic intraocular lens due to nontraumatic iris laxity. Eur J Ophthalmol. 2012;22(3):481-484.

19. Klaproth OK, Rehrmann J, Kohnen T. Dynamic positional change and defocus curve of a phakic foldable anterior-chamber angle-supported intraocular lens during accommodation. Ophthalmology. 2013;120(7): 1373-1379.

20. Cheng H, Jacobs P, Price N, Moar I. Anterior chamber profile and lens implant movement - a high-speed cinematographic study. Trans Ophthalmol Soc U K. 1982;102(Pt 1):21-23.

21. Jacobs PM, Cheng H, Price NC. Pseudophakodonesis and corneal endothelial contact: direct observations by high-speed cinematography. Br J Ophthalm. 1983;67(10):650-654.

22. Sekundo W, Bissmann W, Tietjen A. Behaviour of the phakic irisclaw intraocular lens (Artisan/Verisyse) during accommodation: an optical coherence biometry study. Eur J Ophthalmol. 2007;17(6): 904-908.

23. Doors M, Eggink FA, Webers CA, Nuijts RM. Late-onset decentration of iris-fixated phakic intraocular lenses: a case series. Am J Ophthalmol. 2009;147(6):997-1003, 1003.e1-e2. 
24. Menezo JL, Aviño JA, Cisneros A, Rodriguez-Salvador V, MartinezCosta R. Iris claw phakic intraocular lens for high myopia. $J$ Refract Surg. 1997;13(6):545-555.

25. Pérez-Santonja JJ, Bueno JL, Zato MA. Surgical correction of high myopia in phakic eyes with Worst-Fechner myopia intraocular lenses. $J$ Refract Surg. 1997;13(3):268-281; discussion 281-264.
26. Nyström M, Hooge I, Holmqvist K. Post-saccadic oscillations in eye movement data recorded with pupil-based eye trackers reflect motion of the pupil inside the iris. Vision Res. 2013;92:59-66.

27. Schaeffel F. Binocular lens tilt and decentration measurements in healthy subjects with phakic eyes. Invest Ophthalmol Vis Sci. 2008; 49(5):2216-2222.

\section{Publish your work in this journal}

Clinical Ophthalmology is an international, peer-reviewed journal covering all subspecialties within ophthalmology. Key topics include: Optometry; Visual science; Pharmacology and drug therapy in eye diseases; Basic Sciences; Primary and Secondary eye care; Patient Safety and Quality of Care Improvements. This journal is indexed on

Submit your manuscript here: http://www.dovepress.com/clinical-ophthalmology-journal

\section{Dovepress}

PubMed Central and CAS, and is the official journal of The Society of Clinical Ophthalmology (SCO). The manuscript management system is completely online and includes a very quick and fair peer-review system, which is all easy to use. Visit http://www.dovepress.com/ testimonials.php to read real quotes from published authors. 